\title{
Predicting the Impacts of the COVID-19 Pandemic on Food Supply Chains and Their Sustainability: A Simulation Study
}

\author{
Yakun Huang $\mathbb{D},{ }^{1}$ Jack Li $\mathbb{D},{ }^{1}$ Yuan Qi $\mathbb{D},{ }^{2}$ and Victor Shi $\mathbb{D}^{1}$ \\ ${ }^{1}$ Lazaridis School of Business and Economics, Wilfrid Laurier University, N2L3C5, Waterloo, Canada \\ ${ }^{2}$ School of Business Administration, Shanghai Lixin University of Accounting and Finance, Shanghai, China \\ Correspondence should be addressed to Yuan Qi; qiyuan@lixin.edu.cn
}

Received 7 October 2021; Accepted 1 December 2021; Published 31 December 2021

Academic Editor: Lei Xie

Copyright ( 2021 Yakun Huang et al. This is an open access article distributed under the Creative Commons Attribution License, which permits unrestricted use, distribution, and reproduction in any medium, provided the original work is properly cited.

The COVID-19 pandemic has continued to result in severe disruptions to food supply chains. In this research, we present a simulation study on the impact of the COVID-19 pandemic on food supply chains and their sustainability using the lobster industry in Nova Scotia, Canada, as an example. The main contributions of this paper are twofold. First, it analyzes how the pandemic has negatively disrupted lobster supply chains and their sustainability. Second, it demonstrates how a simulation-based methodology based on the software AnyLogistix can be applied to examine the effects of a pandemic on food supply chains. We show the impacts of the COVID-19 pandemic from four perspectives: production-inventory dynamics, customer performance, financial performance, and lead-time performance. Our findings include the following. First, the pandemic has created a backlog problem for the live lobster industry. Second, it has significantly increased the lead time of the lobster supply chain. Overall, this research can help the government and trade organizations to devise appropriate policies to reduce the negative impacts of the pandemic on food supply chains and their sustainability.

\section{Introduction}

Over the past several decades, global supply chains have become critical to the success of many firms and industries. Moreover, firms and industries have adopted systems such as "just in time," "build to order," and "vendor managed inventories" to become efficient [1]. However, this has made them more vulnerable to supply chain disruptions, especially those caused by crises [2].

In the month of January 2020, many manufacturers were shut down in China due to the COVID-19 pandemic. This created a severe disruption of global supply chains as China is an important supplier of numerous raw material and intermediate goods to countries across the world. On March 11, 2020, the World Health Organization (WHO) announced the novel coronavirus disease as a pandemic, given that there were more than 121,000 cases in 118 countries. The crisis has caused simultaneous global disruptions to both supply and demand. On March 24, the Ontario, Canada, government announced a shutdown of all nonessential businesses. Restaurants were only able to offer take-out, drive-through, and delivery services. As a result, many food manufacturers have been forced to destroy their products due to a lack of buyers because of the closure of restaurants, schools, and food service businesses, hurting the Canadian food supply chains [3]. Hence, it is important to study how the pandemic has affected Canadian food supply chains.

The goals of this paper are twofold. The first is to analyze how the COVID-19 pandemic has negatively disrupted Canadian food supply chains from four perspectives: production-inventory dynamics, customer performance, financial performance, and lead-time performance. The second is to demonstrate how the simulation-based methodology can be used to examine and predict the effects of the pandemic on food supply chains. To achieve these two goals, we conduct a simulation study to analyze how Canadian food supply chains have been disrupted by the COVID-19 pandemic using lobster industry in Nova Scotia as an example. As demonstrated by Klibi and Martel [4] and 
Cannella et al. [5], simulation models are effective for analyzing supply chains under uncertain conditions.

For the simulation in this research, we adopt the AnyLogistix software to analyze the complex supply chain system for the Canadian lobster industry. Moreover, we identify the supply chain behavior by examining individual components and how they interact at different stages. As demonstrated by Ivanov [6], the AnyLogistix has been widely adopted to analyze supply chain risk and resilience. Following Ivanov [6], we build a standard AnyLogistix model with "SIM Global Network Examination" to analyze the large-scale problem. Note that the AnyLogistix software is also adopted in several latest studies on supply chain disruptions such as Moosavi and Hosseini [7], which provide more theoretical support for our methodology.

The rest of this paper is structured as follows. Section 2 reviews the literature related to pandemics and simulationbased methodologies. Section 3 presents the detailed simulation model based on the AnyLogistix software to examine the impacts of the COVID-19 pandemic on supply chains and their sustainability. Section 4 discussed the experimental results for the lobster supply chain in Novita Scotia. Finally, Section 5 concludes the paper by summarizing the main contributions and conclusions in the paper.

\section{Literature Review}

During the past several decades, an increasing number of epidemic or pandemic outbreaks worldwide have been witnessed $[6,8]$. While there are quite a few studies on the impacts of epidemic outbreaks through the humanitarian logistic point of view, the literature on the impact of pandemic outbreaks on commercial supply chains is still rare [6]. Furthermore, Ivanov and Dolgui [9] argue that the simulation-based methodology is effective when using timedependent parameters and analyzing capacity degradation and recovery. To be more specific, the simulation-based methodology has the advantage when handling complex problem settings with changing logical and randomness constraints. Besides, the AnyLogistix software is useful when constricting the supply chains paths. It constitutes a complete set of technologies to build a digital supply chain $[7,9,10]$.

Next, we first review related studies regarding the impacts on supply chains generated by pandemics in Section 2.1. In Section 2.2, we then review studies on how simulation models can be applied to analyze the consequent disruption risks.

2.1. Epidemic Outbreaks and Supply Chains. An epidemic outbreak can greatly affect a food supply chain through "disruption propagation in the supply chain and epidemic outbreak propagation in the population" and also through "disruption in the infrastructure of logistics, demand, and supply" (p. 20 of [11]). The spread speed of epidemic outbreaks is much more rapid than other disruptions [12]. Supply chains involve producing and delivering products starting from different suppliers to final consumers. Food supply chains contain several interdependent steps and operations, such as supplier, distribution center, food processing, and consumer handling, to deliver food products from suppliers all the way to the end customer. They are often more focused on product quality and environmental sustainability demand [13]. Furthermore, the increasing globalization of food supply chains means that a lack of response to food crises could cause severe problems in health and trade [14]. For example, Johanis [15] reported a pandemic response plan designed for Toronto Pearson Airport to limit the negative effect of the SARS epidemic outbreaks around 2002-2003. This virus adversely affected the airline industry, which indirectly affected food supply chains.

However, the long response time from the government caused the negative effect from the SARS epidemic to be doubled [15]. In 2013, the avian influenza H7N9 spreading in China created a short-run economic loss in China's poultry meat supply chain [16]. Similarly, the Ebola outbreak in West Africa caused over 4500 deaths in 2014, with several national health authorities requiring the affected regions to remain isolated for the entire duration due to Ebola's strong ability to spread, and it caused a delay of shipments anywhere from 10 to 21 days due to the high-security level regulation from the government [17]. In this case, the output for agricultural products shrank as the epidemic outbreak spread further [17].

Before the pandemic occurred, Canada's Food Price Report expected food prices to increase by $2 \%-4 \%$ in 2020 due to climate change, geopolitical risks, currencies, and the trade environment [18]. The COVID-19 pandemic has had several impacts on the Canadian food industry. Canada announced new measures to support local farmers and agri-food businesses two weeks after the World Health Organization declared the global outbreak of COVID-19 pandemic on March 11 [19]. The pandemic has caused operational sustainability for farmers, and it is expected to make food prices more volatile. Moreover, farmers are forced to deal with the impact of the pandemic and restart operations after Stage 3 of the reopening when all business and public spaces are permitted to open. Besides, a surplus of unsold goods has been caused by collapsing demand for their food products due to the closure of all nonessential business because of the pandemic. In May 2020, the Canadian Pork Council estimated that there was a surplus of 140,000 pigs in eastern Canada, with a $\$ 675$ million loss expected for the industry [20]. The Canadian Cattlemen's Association also announced that the beef industry lost around $\$ 500$ million at the end of June due to the collapse in production which was caused by the pandemic [20]. Thus, the pandemic further slowed down the food processing times and generated long-lead times for factories which had a negative impact on Canadian food production industry. As a result, the coronavirus pandemic has caused and will continue to cause negative impacts, such as financial losses and collapses in productions, to Canadian food supply chains. 
2.2. Simulation-Based Supply Chains' Modelling. Dynamic simulation models are shown to be useful to analyze supply chain behavior [6]. In addition, simulation studies are generally used for analyzing supply chain risks by incorporating methods such as agent-based methods and system dynamics methods [10, 21-23]. Klibi and Martel [4] demonstrate that simulation-based models are particularly useful for analyzing the impacts on supply chains under certain conditions or changes. However, there are few articles which combine simulation-based methodology with disruptions to analyzing the effect of epidemic outbreaks on supply chains [24].

As indicated by Ivanov and Dolgui (p. 3 of [9]), the simulation-based methodology demonstrates the impact from two aspects, logical and randomness constraints, such as "randomness in disruptions, inventory, production, sourcing, shipment control policies, and gradual capacity degradation and recovery." Moreover, simulation-based methodologies are designed to analyze the impacts of disruptions on supply chains under time-dependent changes $[4,6]$. It is valuable to determine the impact of epidemic outbreaks on supply chains, as discussed previously. For instance, with the coronavirus pandemic in 2020, all nonessential businesses were shut down, and it disrupted local food supply chains. By generating detailed control policies, epidemic outbreaks can be analyzed using financial, customer, and operational performance data from various indicators $[6,25]$.

In order to solve food quality and sustainability issues, Van der Vorst et al. [26] introduced a new simulation model, the ALADIN ${ }^{\mathrm{TM}}$ (Agro-Logistic Analysis and Design Instrument), to analyze the potential problems of food supply chains. The model presents the impact of changes in food supply chains by changing the environmental conditions and keeping track of quality and sustainability indicators in the model. However, the ALADIN ${ }^{\mathrm{TM}}$ model is not ideal when it is used to analyze time-dependent cases because it takes a long time to build and analyze. Furthermore, it is not appropriate to study the short-run impacts on food supply chains when analyzing the effect of epidemic outbreaks [26]. Compared with the ALADIN ${ }^{\mathrm{TM}}$ model, anyLogistix provides a more accurate way to generate a simple simulation-based model which creates a resilience analysis, and it can also incorporate responses to short-run effects while analyzing time-dependent parameters $[6,27]$. It can provide a combination of simulation, poetization (CPLEX), and performance visualization of supply chains. It also constitutes a complete set of technologies to build a digital supply chain $[9,10]$. Therefore, anyLogistix is a good candidate for a model that can determine time-dependent parameters and evaluate the impacts of disruptions within certain time periods.

Ivanov [6] points out that it is important to build a simulation-based model by using anyLogistix software. It indicates that, by comparing the speed of the pandemic propagation and the duration of the pandemic length, the different reactions of supply chains impacted by the pandemic can be observed. Moreover, during epidemic outbreaks, the reaction of supply chains depends on the timing and ripple effect. It also depends on the sequence that various facilities close and open in the different stages during outbreaks [6]. Meanwhile, the disruption in both supply and demand during the epidemic outbreaks may have a positive effect on supply chains based on the people's reaction to outbreaks [6]. Overall, the simulation model has the advantage of handling complex problems when the situational behavior changes in the model over time, such as stopping the supply of products during certain periods [6].

\section{The Simulation Model}

A simulation model is designed to create a digital prototype using real-world data to analyze the performance of the system to be simulated. In the food industry, simulation models are often used when the logistics of the supply chains encounter uncertainties [26].

3.1. Simulation Model Design. Ivanov [6] confirms that the standard AnyLogistix model "SIM Global Network Examination" is very effective for analyzing large-scale problems, such as customer service and risk management, and examining the scalability and the accuracy of the result for the model. We set the appropriate parameters of the model based on different stages of the live lobster market. According to Aucoin [28], the standard lobster supply chains contain four parts: customer, food service or retailer, distributor, and suppliers.

As illustrated in Figure 1, two suppliers are in Halifax and Digby, and they are the two top volume lobster producers in Nova Scotia. These two suppliers supply live lobsters to two distribution centers, who in turn distribute them to four factories or food service in Montreal, Vancouver, Edmonton, and Toronto. Factories then use these live lobsters from the distribution center to supply both live lobster and lobster-related products to 47 customers near them. These customers are generated using the AnyLogistix software by setting a minimum city population of 15,000 .

Recent studies indicate that supply chain performance mainly rely on the timings and the events that are provided for a model [6]. Therefore, we input several events into the model based on recent real-world events. For example, several provincial governments decided to shut down all nonessential businesses on March 15th, 2020. Furthermore, consumption dropped by $40 \%$, causing several production lines to shut down after March 15th due to the lack of buyers, with all factories shut down after March 15th for 30 days because several employees had been affected by the disease. It caused the lobster factories to temporarily close for health surveys, masks, and temperature checks. Suppliers in Nova Scotia stopped supplying products for 30 days since the coronavirus pandemic has crushed the markets and caused the demand for live lobster to drop dramatically [29].

In addition to the above, paths (such as from distributor to factories) and events are required when creating the model. Paths indicate how supply chains work for the Canadian lobster industry and offer a general overview of the model. Events are generated as the trigger for the pandemic 


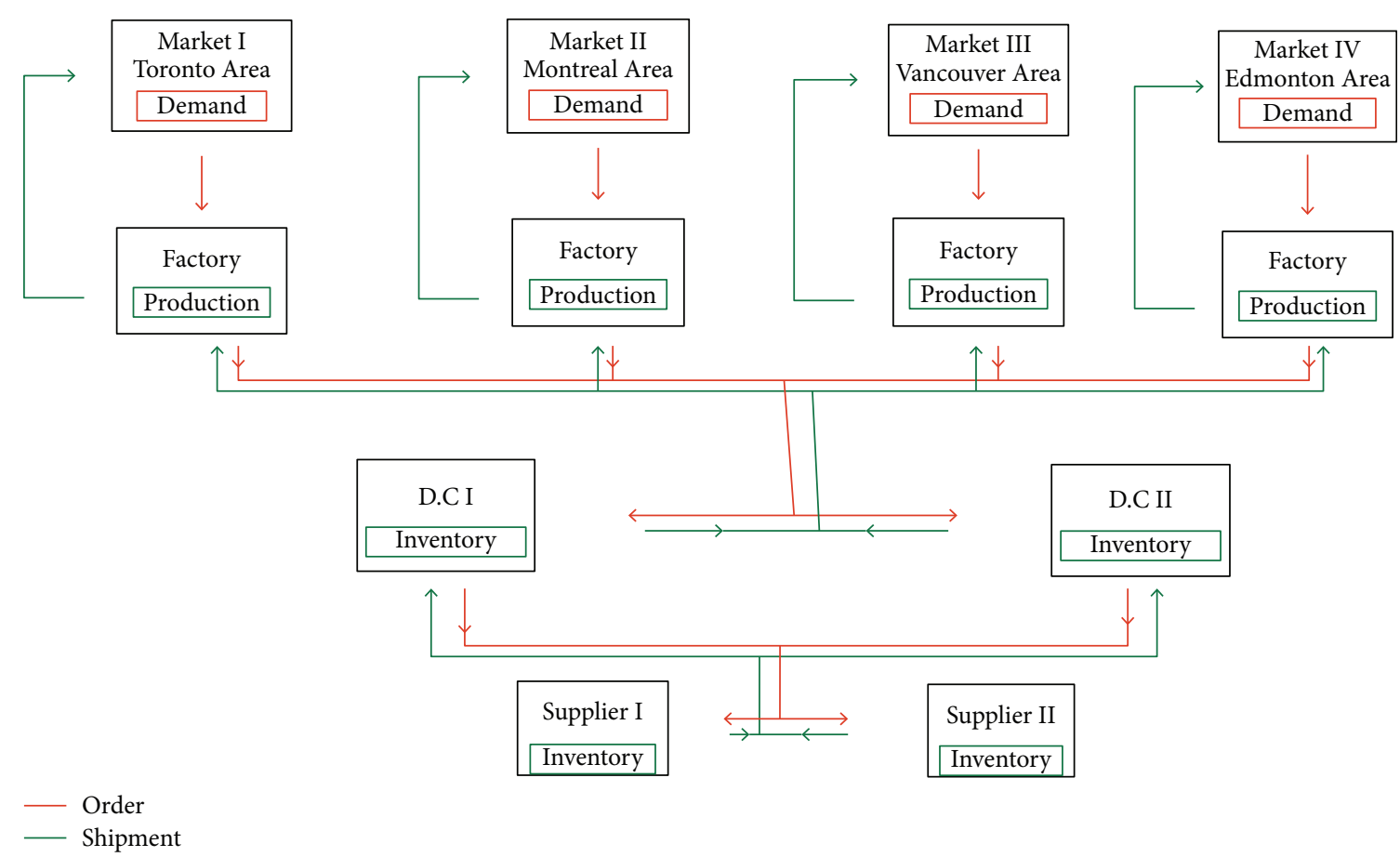

FIgURE 1: The lobster supply chain.

within the model and add in external affects to the model. As a result, the model can demonstrate the impact of the coronavirus pandemic specifically.

3.2. Data. As demonstrated by Anparasan and Lejeune [8], several fundamental pieces of data are required while generating the model, such as geographic location data, leadtime data, and demand data.

3.2.1. Geographic Location Data. The geographic location data are generated using the software by setting the number of customers as 50 and the minimum city population as 15,000. Thus, the software will automatically generate 50 customers from different cities in Canada when it has more than 15,000 people. Customers are ordering products from factories every five days. Based on the location, the latitude and longitude of customer's location are generated automatically, which are used when calculating the transportation costs. In general, suppliers are using airplanes to ship their live lobster to distribution centers, and distribution centers and factories use trucks to deliver products, and most of the orders from factories are delivered by FedEx [30].

3.2.2. Lead-Time Data. It shows the time between sending the products and completion of the delivery process. Shipping by trucks often takes 2 to 3 days to deliver live lobster to the distribution center and takes 1 to 2 days to provide live lobster to factories. Customers are expected to get their products within two days before March 15th [30]. After March 15th, factories are shutting down, which generated long-lead time for customers. As a result, all lead- time orders will extend between 2 and 3 days. However, the expected lead time for customers is only three days [30]. The extended delivery time negatively affects the ELT (expected lead time) service level, which is the ratio of products delivered on time to the overall number of products shipped.

3.2.3. Demand Data. The demand data show the amount that customers order from the factories. Customers will order entirely based on their demand, and it is often between 4 to 80 lbs per order before March 2020. During the pandemic, demand will decrease by $40 \%$, since all nonessential businesses are shut down, including restaurants. Since most lobsters are sold at restaurants; therefore, the demand for lobster drops dramatically. Furthermore, the initial order for lobster is indeed low. Following Ivanov [6], the primary purpose of this model is to determine the impact of disruption due to the pandemic. Therefore, we will omit several variables, such as $\mathrm{CO}_{2}$, from facilities and processing and loading and unloading gates.

Other variables are also considered in the model, such as price flow and distribution type for factories and distribution centers. From Figure 2, the price that suppliers sell live lobsters to disruption center is around $\$ 6.5$ per lbs., and distributors sell live lobsters to factories by $\$ 9.0-\$ 9.5$ per lbs. [28]. Factories are then using these live lobsters to make lobster-related products, and sell both live lobster and lobster-related products to the customer by \$10-12 per lbs. [28]. The price for products is continually increasing yearly with a minimal amount. Besides, factories and distribution centers split the demand equally to each of the available sources, which simultaneously supply the customers. Based on the data and the supply chain design as illustrated in Figure 3, we can run the simulation experiment and 


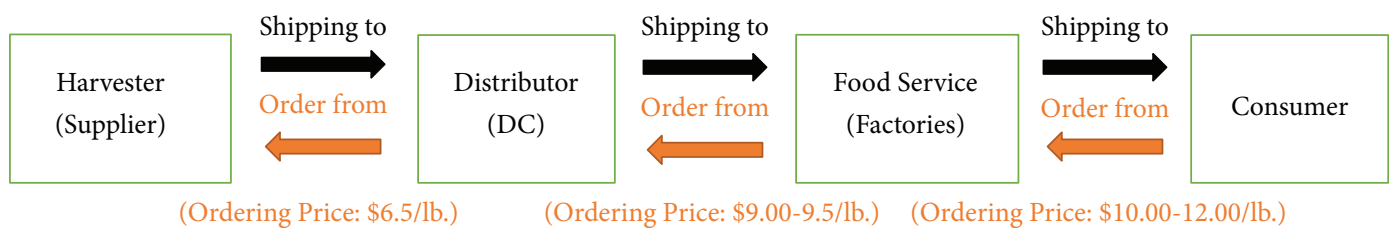

FIgURe 2: Product and price flows. Note: the figure is adapted from direct marketing of Cape Breton lobster and its impact on the triple bottom line of fishery performance (p 17 of [28]).

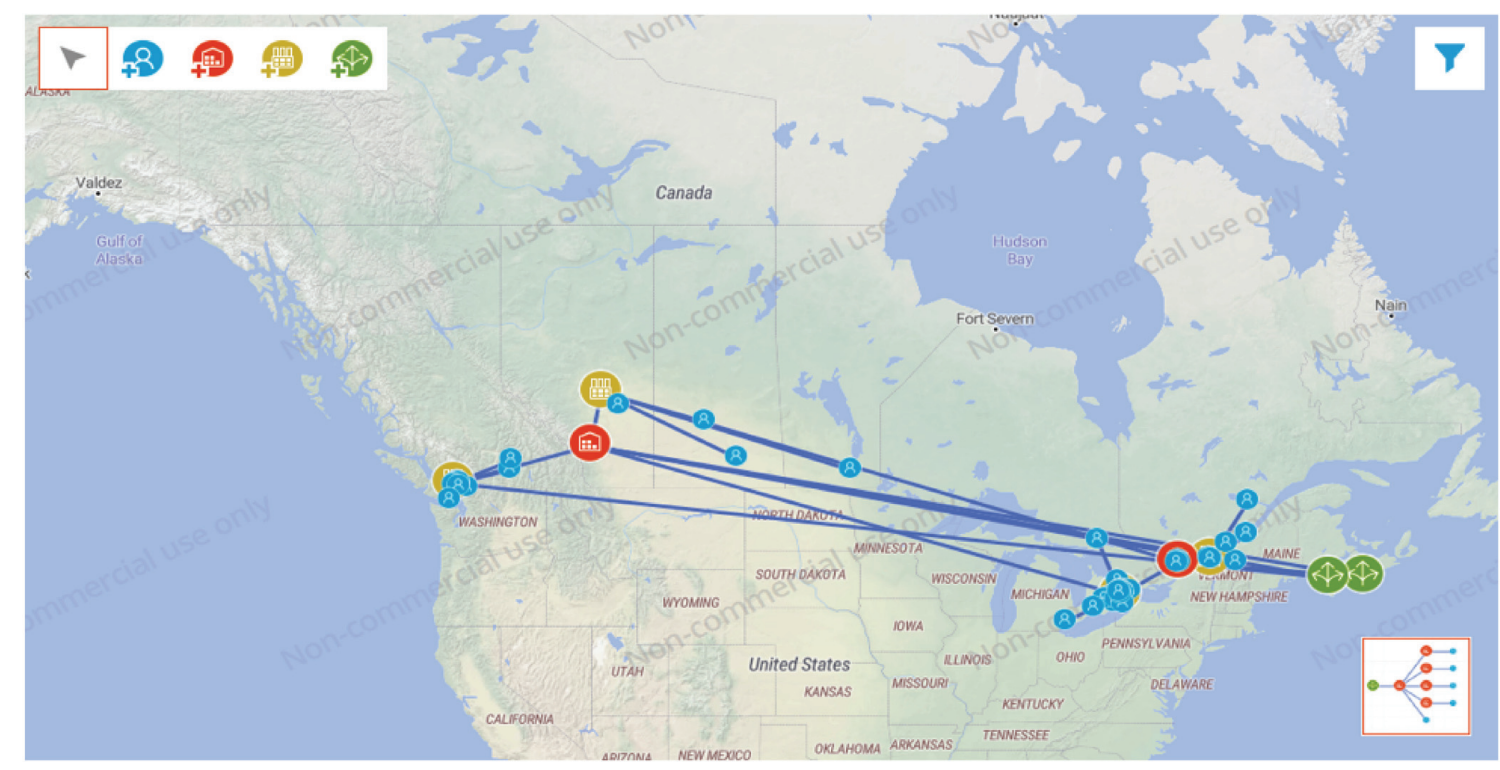

- March 15 Consumption for live lobsters drops around 30\%

- April 15 Production line for live lobster shutdown

- April 20 DCs temporarily closed

- May 6 DCs reopen

- May 15 Production line for live lobsters reopen

FIGURE 3: Supply chain design (screenshot from anyLogistix ${ }^{\mathrm{TM}}$ ). (i) March 15: consumption for live lobsters drops around 30\%. (ii) April 15: production line for live lobster shutdown. (iii) April 20: DCs temporarily closed. (iv) May 6: DCs reopen. (v) May 15: production line for live lobsters reopen.

TABLE 1: Total production.

\begin{tabular}{lccc}
\hline & Products & Value & Total production (lbs.) \\
\hline 1 & Live lobster & $18,131.4$ & Production unit \\
2 & Lobster products & $21,153.8$ & Production unit \\
\hline
\end{tabular}

compute the statistics results using AnyLogistix software. Note that we have conducted simulations using other input values and obtained similar results.

\section{Simulation Results and Discussion}

Following the models of Ivanov [6] and Aucoin [28], we tested the impact of the pandemic on the supply chain performance of the lobster industry in Canada. Our analysis and results consist of the following four parts: (1) production-inventory dynamics (as summarized in Table 1), (2) customer (ET service level) performance, (3) financial performance, and (4) lead-time performance. Next, we will present more details for each part.
4.1. Production-Inventory Dynamics. Figure 4 shows the available inventory for live lobster and lobster products including backlog. The $y$-axis is the total inventory including backlog for suppliers, distribution centers, and factories in total. The trend defined the difference between available inventory and demand. Furthermore, inventories for suppliers are checked every 60 days, and inventory distribution center and factories are checked every 30 days. However, they stop producing and checking between day 75 to day 120 due to the pandemic.

The present backlog problem for the live lobster industry caused the stock of lobster to collapse. Suppliers are not able to sell the same amount of lobster than before, so the inventory for live lobster keeps increasing. Figure 4 shows the inventory including backlog for live lobsters, keeps increasing in the short run from day 150 to day 300. However, the extra backlog starts to decrease as the pandemic's effect becomes lighter and eventually returns to the organic level in the long run. Still, the disruption will last at least one year. From the supplier side, they cannot throw captured lobsters 


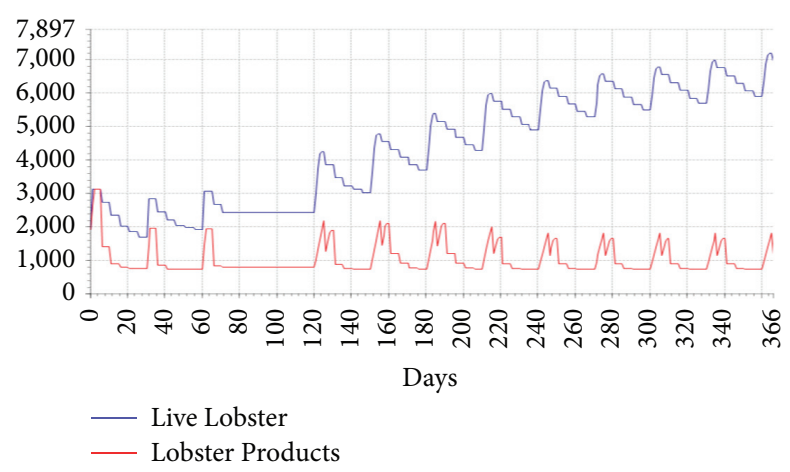

Figure 4: Available inventory including backlog (lbs.).

back into the sea because they need to protect young lobsters and female lobsters with eggs. Thus, the crash in price will generate negative effects on each stage of the supply chain.

4.2. Customer (ELT Service Level) Performance. The ELT service level shows customer performance which is the ratio of products delivered on time to the overall number of products shipped. It is calculated as follows:

ELT service level by products $=\frac{\text { Products in the on time orders }}{\text { Products in the outgoing orders }}$.

As shown in Figures 5 and 6, the ratio is equal to 1 before day 75 (pandemic start) and drops dramatically after the pandemic started. Before the epidemic, the expected lead time for customers is two days, but after the pandemic, the expected lead time becomes longer. As the effects of the pandemic begin to take place, factories begin shutting down and stop sending out orders to customers. Thus, the ratio for ELT service level drops dramatically after day 75. However, it will gradually increase after day 130 as the pandemic's effect becomes smaller. From Figure 6, it shows that compared with other factories, the factory in Toronto has been affected by the pandemic the most, and the Edmonton factory has been affected by the pandemic at the least. This is due to the high volume of ordering from the Toronto factory as opposed to the Edmonton factory.

4.3. Financial Performance. Figure 7 shows the profit, revenue, and total cost for suppliers, distribution centers, and factories in total. It comes from selling products to customers and shows the lobster industry is still able to generate profit during the pandemic since the blue column is above zero. More detailed information is provided in Table 2. Moreover, compared with other costs, such as facility cost and production cost, the outbound processing cost is the most expensive process in the supply chain. Thus, the total revenue for all three paths is around 368 million per year during the pandemic based on the data we input.

4.4. Lead-Time Performance. The lead time shows on the delivery time of every ordered product item. It updates each

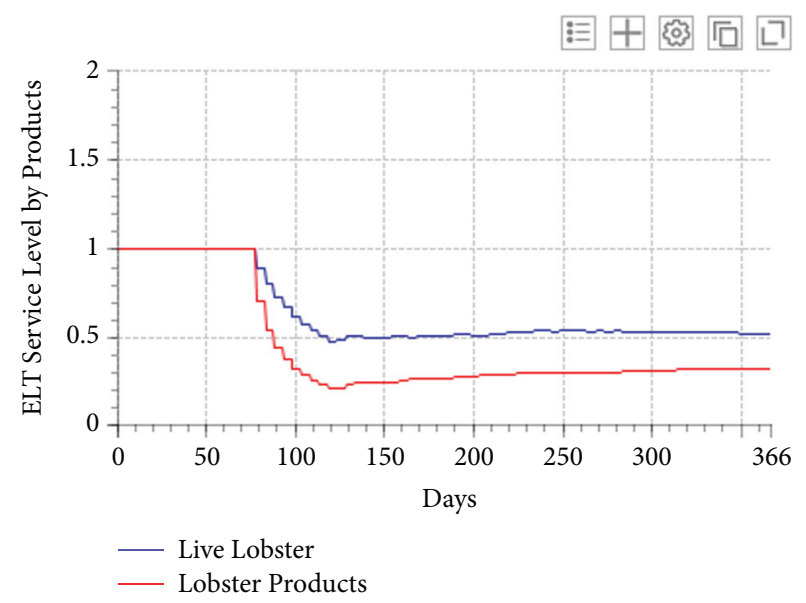

FIGURE 5: ELT service level by products (per product).

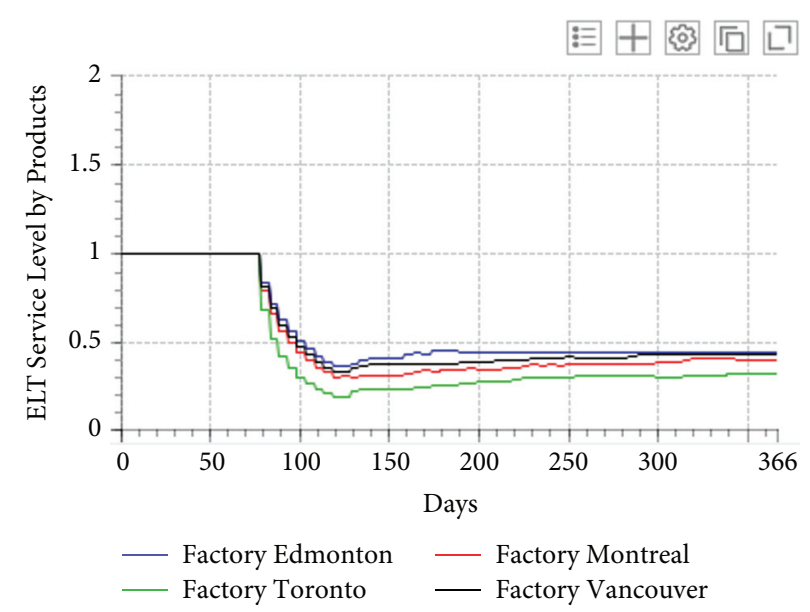

Figure 6: ELT service level by products (per source).

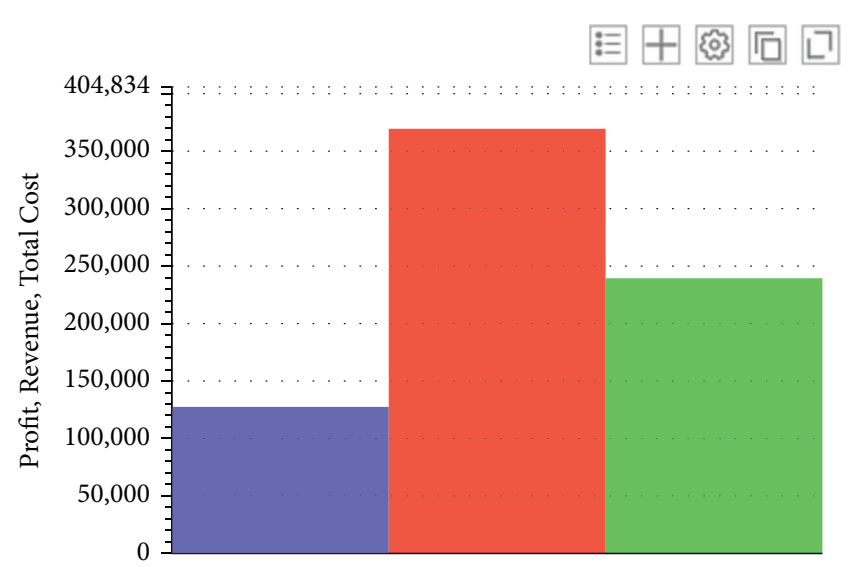

FIgURE 7: Profit, revenue, and total cost chart. Note: blue represents profit; red represents revenue; green represents total cost.

time a shipment with the order is delivered, and all delivered orders are considered no matter if they are on time or delayed. The $y$-axis for graph five shows the total lead time for delivered orders in each factory. Figure 8 shows that, 
Table 2: Profit and loss statement.

\begin{tabular}{lccc}
\hline & & Value (\$) & Unit \\
\hline 1 & Facility cost & 7998.25 & USD \\
2 & Inventory carrying cost & 9572.95 & USD \\
3 & Inventory spend & 977.7 & USD \\
4 & Other cost & 23.37 & USD \\
5 & Outbound processing cost & 105112.2 & USD \\
6 & Production cost & 45326.5 & USD \\
7 & Transportation cost & 70200 & USD \\
8 & Revenue & 368031.2 & USD \\
\hline
\end{tabular}

Note: the dollar amounts are in thousands.

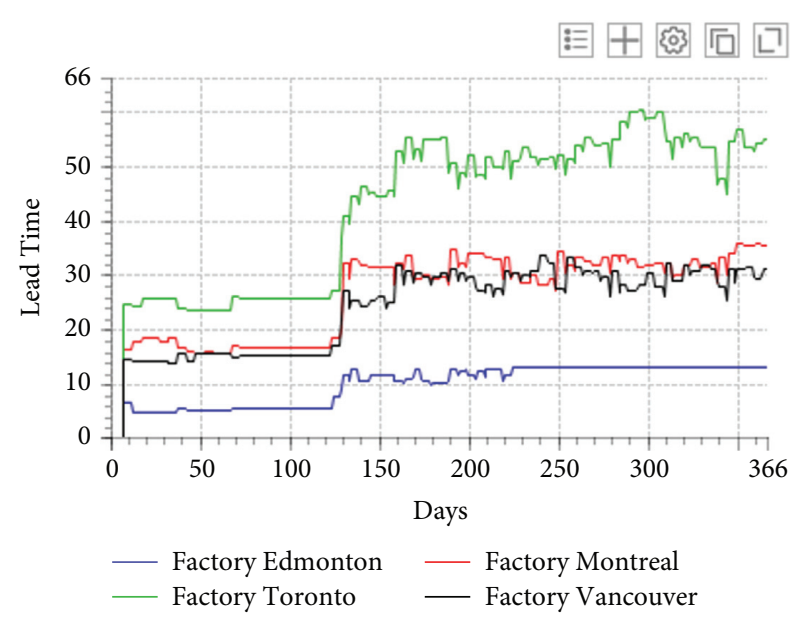

Figure 8: Lead times for different factories.

before day 120, each factory's lead time is consistent, but after the pandemic, the lead time almost doubled for each factory. Compared with other factories, the lead time for the Toronto factory is increasing significantly and is approaching 60 days in day 300, which is double the lead time before day 120. Besides, the lead time for Edmonton has been affected by the pandemic the least. Even though the lead time doubled after day 120 , it becomes more consistent after day 220. Figure 9 represents the mean lead time for delivering products to the customer, and it presents a similar result for Figure 8. It shows that, before day 120, the mean lead time for factories is around 1.5 days, and it is approaches three days after day 120 .

As shown in this case study of the lobster industry, the pandemic could create backlog problems, and it is the same for other food industries. The closing of suppliers and factories caused the collapse of products. It also caused factories take a longer time to deliver products to customers. The long-lead time further pushes down the demand. Furthermore, the effect will last at least one year and generate long-term negative effect for the society. To support the industry, the government initiated several polices to assist food industries. The $\$ 77.5$ million emergency processing fund to assist food processors and the surplus food purchase program is a $\$ 50$ million fund to redistribute surplus commodities (support for Canada's food supply system, 2020). As a result, it helps food processors to adjust

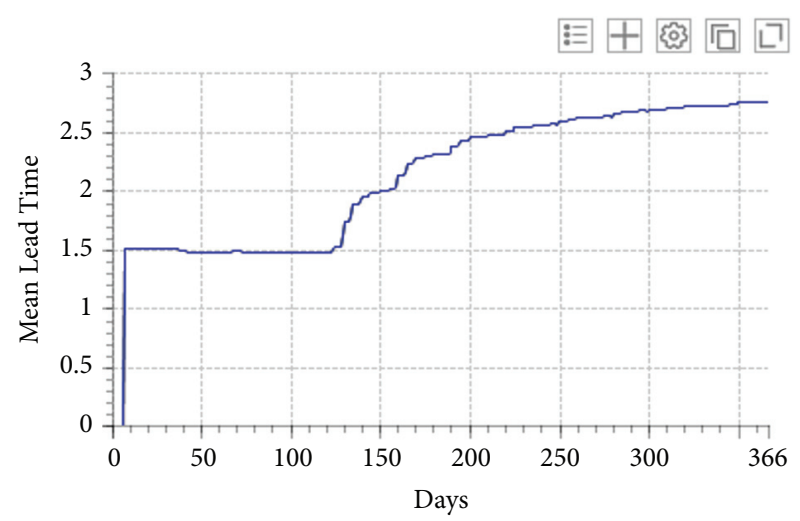

Figure 9: Mean lead time.

operations and continue production during the pandemic by upgrading their equipment and introducing automation.

Based on the case study, we examined the importance of the simulation-based model while studying food supply chains. Furthermore, we find that more extended epidemic propagation delays mainly cause a decrease in supply chain performance, for example, the sequence of facility closing and operating at different stages and the decrease in product demand caused by the events. In general, the model is able to observe the combined effects of several adverse events. This is imperative when examining the epidemic outbreaks because they have the potential to cause negative impacts to several aspects of supply chains at the same time. Thus, it shows that simulation-based methodology is useful when analyzing the impact of pandemic.

\section{Conclusions and Future Research}

5.1. Conclusions. This paper examined how the COVID-19 pandemic negatively disrupted the Canadian food supply chains by using the lobster industry in Nova Scotia as a case study. Simulation results are obtained using the software AnyLogistix on four dimensions of supply chain performance: production-inventory dynamics, customer performance, financial performance, and lead-time performance.

To be more specific, based on the simulation results obtained in this paper, firstly, we show the pandemic caused a backlog problem for food processors. In order to sell these products, suppliers decrease their prices. This causes a crash in price and hurts the industry overall. In addition, it creates long-lead times for customers and doubled the shipping time from food processors. The long-lead time caused the demand to drop and further decreases the industry profits. Secondly, we demonstrate how simulation-based methodology can be used to examine and predict pandemics' impacts on food supply chains. By generating the sequence of facility closing and operating at different stages, we can observe the combined effects from several negative events associated with epidemic outbreaks. Furthermore, our results demonstrate clearly that the impacts of the pandemic will last at least a year and the industry will recover slowly. Managers and policy makers can use the outcomes of this research to predict and analyze the impact of epidemic 
outbreaks on food supply chains in Canada. In this way, the food supply chain can recover from this pandemic as soon as possible. As a result, food loss and waste can also be minimized [31]. This would be a great contribution to sustainability because, first, food production consumes tremendous amounts of fresh water, land, energy, and chemicals. Second, most of the food waste ends up in landfills emitting a huge amount of methane, a greenhouse gas at least 25 times more harmful than carbon dioxide [32].

5.2. Research Limitations. As for the limitations, in this research paper, we build a simplified model so that we focus more on the impact of the COVID-19 pandemic. We lack some specific information when generating the model. Because it is a brand-new topic, we are still experiencing the pandemic; some data have not been posted while working on this research paper, such as the total amount of production decreased due to the pandemic in 2020. In future research, we will be using the simulation-based model to analyze the pandemic's impact on food supply chains worldwide. For example, suppliers and factories worry about selling their products to China since the Chinese border is closed during the pandemic. It has caused agricultural product exports to China to drop dramatically, which hurts the Canadian agriculture industry. Hence, in future research, we can use a simulation-based model to analyze the impact of epidemic outbreaks on agricultural supply chains.

\section{Data Availability}

The data used to support the findings of the study are available from the corresponding author upon request.

\section{Conflicts of Interest}

The authors declare that they have no conflicts of interest.

\section{References}

[1] J. Martha and S. Subbakrishna, "Targeting a just-in-case supply chain for the inevitable next disaster," Supply Chain Management Review, vol. 6, no. 5, pp. 18-23, 2002.

[2] A. Norrman and U. Jansson, "Ericsson's proactive supply chain risk management approach after a serious sub-supplier accident," International Journal of Physical Distribution \& Logistics Management, vol. 34, no. 5, pp. 434-456, 2004.

[3] N. Powell, "“Unlike anything we've seen before": coronavirus lockdowns strain critical supply-chains in Canada," 2020, https://financialpost.com/transportation/unlikeanything-weve-seen-before-coronavirus-lockdowns-straincritical-supply-chains-in-canada.

[4] W. Klibi and A. Martel, "Modeling approaches for the design of resilient supply networks under disruptions," International Journal of Production Economics, vol. 135, no. 2, pp. 882-898, 2012.

[5] S. Cannella, R. Dominguez, J. M. Framinan, and M. Bruccoleri, "Demand sharing inaccuracies in supply chains: a simulation study," Complexity, vol. 2018, Article ID 1092716, 13 pages, 2018.

[6] D. Ivanov, "Predicting the impacts of epidemic outbreaks on global supply chains: a simulation-based analysis on the coronavirus outbreak (COVID-19/SARS-CoV-2) case," Transportation Research Part E: Logistics and Transportation Review, vol. 136, pp. 1-14, 2020.

[7] J. Moosavi and S. Hosseini, "Simulation-based assessment of supply chain resilience with consideration of recovery strategies in the COVID-19 pandemic context," Computers \& Industrial Engineering, vol. 160, Article ID 107593, 2021.

[8] A. A. Anparasan and M. A. Lejeune, "Data laboratory for supply chain response models during epidemic outbreaks," Annals of Operations Research, vol. 270, no. 1/2, pp. 53-64, 2018.

[9] D. Ivanov and A. Dolgui, "A digital supply chain twin for managing the disruption risks and resilience in the era of industry 4.0," Production Planning \& Control, vol. 32, 2020.

[10] D. Ivanov, A. Pavlov, A. Dolgui, D. Pavlov, and B. Sokolov, "Disruption-driven supply chain (re)-planning and performance impact assessment with consideration of pro-active and recovery policies," Transportation Research Part E: Logistics and Transportation Review, vol. 90, pp. 7-24, 2016.

[11] K. Govindan, H. Mina, and B. Alavi, "A decision support system for demand management in healthcare supply chains considering the epidemic outbreaks: a case study of coronavirus disease 2019 (COVID-19)," Transportation Research Part E: Logistics and Transportation Review, vol. 138, Article ID 101967, 2020.

[12] Y. He and N. Liu, "Methodology of emergency medical logistics for public health emergencies," Transportation Research Part E: Logistics and Transportation Review, vol. 79, pp. 178-200, 2015.

[13] J. G. Van der Vorst and A. J. Beulens, "Identifying sources of uncertainty to generate supply chain redesign strategies," International Journal of Physical Distribution \& Logistics Management, vol. 32, no. 6, 2002.

[14] World Health Organization, Food Safety Issues: Terrorist Threats to Food: Guidance for Establishing and Strengthening Prevention and Response Systems, World Health Organization, Geneva, Switzerland, 2002.

[15] D. Johanis, "How toronto pearson international airport applied lessons from SARS to develop a pandemic response plan," Journal of Business Continuity \& Emergency Planning, vol. 1, no. 4, pp. 356-368, 2007.

[16] S. G. Khokhar, Q. Min, and C. Su, "Bird flu (H7N9) outbreak and its implications on the supply chain of poultry meat in China," The Journal of Applied Poultry Research, vol. 24, no. 2, pp. 215-221, 2019.

[17] BSI, "Supply chain impact of 2014 Ebola outbreak," 2014, https://www.bsigroup.com/globalassets/localfiles/aaa/ Whitepaper\%20Ebola_10.14_7.pdf.

[18] Agri-Food Analytics Lab, "Canada's food price report 2020," 2020, https://www.dal.ca/sites/agri-food/research/canada-sfood-price-report.html.

[19] Public Health Agency of Canada and Government of Canada, "Coronavirus disease (COVID-19): outbreak update," 2020, https://www.canada.ca/en/public-health/services/diseases/2019novel-coronavirus-infection.html?topic=tilelink.

[20] T. Seskus, Pandemic Has Rattled-Not Broken-Canada's Meat Supply Chain, but Store Prices Could Still Climb, CBC News, Tornato, ON, USA, 2020, https://www.cbc.ca/news/business/ coronavirus-meat-supply-chain-interrupted-1.5564106.

[21] J. Cui, M. Zhao, X. Li, M. Parsafard, and S. An, "Reliable design of an integrated supply chain with expedited shipments under disruption risks," Transportation Research Part E: Logistics and Transportation Review, vol. 95, pp. 143-163, 2016. 
[22] M. Fattahi, K. Govindan, and E. Keyvanshokooh, "Responsive and resilient supply chain network design under operational and disruption risks with delivery lead-time sensitive customers," Transportation Research Part E: Logistics and Transportation Review, vol. 101, pp. 176-200, 2017.

[23] N. S. Sadghiani, S. A. Torabi, and N. Sahebjamnia, "Retail supply chain network design under operational and disruption risks," Transportation Research Part E: Logistics and Transportation Review, vol. 75, pp. 95-114, 2015.

[24] J. Hackl and D. Thibaut, "Epidemic spreading in urban areas using agent-based transportation models," International Journal of Production Research, vol. 11, no. 4, Article ID 92, 2019.

[25] Y. Li, C. W. Zobel, O. Seref, and D. Chatfield, "Network characteristics and supply chain resilience under conditions of risk propagation," International Journal of Production Research, vol. 223, 2019.

[26] J. G. A. J. Van der Vorst, S.-O. Tromp, and D.-J. Zee, "Simulation modelling for food supply chain redesign; integrated decision making on product quality, sustainability and logistics," International Journal of Production Research, vol. 47, no. 23, pp. 6611-6631, 2009.

[27] R. Aldrighetti, I. Zennaro, S. Finco, and D. Battini, "Healthcare supply chain simulation with disruption considerations: a case study from northern Italy," Global Journal of Flexible Systems Management, vol. 20, pp. 81-102, 2019.

[28] R. Aucoin, Direct Marketing of Cape Breton Lobster and its Impact on the Triple Bottom Line of Fishery Performance, Dalhousie University, Halifax, Canada, 2017, https://dalspace. library.dal.ca/handle/10222/73828.

[29] P. Withers, N.S. Lobster Shipments to China Drop "Dramatically" Due to Coronavirus, CBC News, Toronto, ON, USA, 2020, https://www.cbc.ca/news/canada/nova-scotia/ coronavirus-canada-china-lobster-exports-1.5443266.

[30] Lobster Canada, "Lobster dinners," 2020, https://www. lobstercanada.com/lobsterdinners.htm.

[31] R. Aldaco, D. Hoehn, J. Laso et al., "Food waste management during the COVID-19 outbreak: a holistic climate, economic and nutritional approach," The Science of the Total Environment, vol. 742, Article ID 140524, 2020.

[32] D. Gunders, Wasted: How America Is Losing up to 40 Percent of its Food from Farm to Fork to Landfill, Natural Resources Defense Council Issue Paper, New York, NY, USA, 2012. 